\title{
REVIEW ARTICLE \\ Mycobacterium bovis (bovine tuberculosis) infection in North American wildlife: current status and opportunities for mitigation of risks of further infection in wildlife populations
}

\author{
R.S. MILLER* AND S. J. SWEENEY \\ USDA, APHIS, Veterinary Services, Center for Epidemiology and Animal Health, Fort Collins, CO, USA
}

Received 31 October 2012; Final revision 1 April 2013; Accepted 2 April 2013;

first published online 9 May 2013

\section{SUMMARY}

Mycobacterium bovis (M. bovis), the causative agent of bovine tuberculosis, has been identified in nine geographically distinct wildlife populations in North America and Hawaii and is endemic in at least three populations, including members of the Bovidae, Cervidae, and Suidae families. The emergence of $M$. bovis in North American wildlife poses a serious and growing risk for livestock and human health and for the recreational hunting industry. Experience in many countries, including the USA and Canada, has shown that while M. bovis can be controlled when restricted to livestock species, it is almost impossible to eradicate once it has spread into ecosystems with free-ranging maintenance hosts. Therefore, preventing transmission of M. bovis to wildlife may be the most effective way to mitigate economic and health costs of this bacterial pathogen. Here we review the status of M. bovis infection in wildlife of North America and identify risks for its establishment in uninfected North American wildlife populations where eradication or control would be difficult and costly. We identified four common risk factors associated with establishment of M. bovis in uninfected wildlife populations in North America,

(1) commingling of infected cattle with susceptible wildlife, (2) supplemental feeding of wildlife,

(3) inadequate surveillance of at-risk wildlife, and (4) unrecognized emergence of alternate wildlife species as successful maintenance hosts. We then propose the use of integrated and adaptive disease management to mitigate these risk factors to prevent establishment of $M$. bovis in susceptible North American wildlife species.

Key words: Adaptive disease management, Bovidae, bovine tuberculosis, Cervidae, Mycobacterium bovis, risk management, Suidae, wildlife.

\section{INTRODUCTION}

Diseases transmitted between wildlife and livestock are increasingly challenging animal health authorities and methods used to mitigate the spread of pathogens. In North America it is estimated that at least $79 \%$ of diseases reportable to the World Organisation for Animal Health (OIE) have a wildlife component [1].

\footnotetext{
* Author for correspondence: R. S. Miller, 2150 Centre Avenue, Bldg B, Fort Collins, CO 80526, USA.

(Email: Ryan.S.Miller@aphis.usda.gov; Ryan.Miller@rsmiller.net)
}

In North America, establishment of Mycobacterium bovis, the causative agent of bovine tuberculosis (bTB), in wildlife is recognized as an impediment to eradication in cattle [2]. M. bovis has one of the broadest host ranges of all known pathogens, affecting many groups of mammals [3]. In some parts of the world, this bacterial pathogen has spilled over from cattle into wildlife, where it has persisted as a reservoir of infection and thwarted efforts to eradicate the disease from farm animal populations. Major freeranging hosts of endemic $M$. bovis infection include the European badger (Meles meles) in the UK and 
Ireland [4-7], brushtail possum (Trichosurus vulpecula) in New Zealand [8, 9], Cape buffalo (Syncerus caffer) and greater kudu (Tragelaphus strepsiceros) in southern Africa [10-12], elk (Cervus canadensis) and American bison (Bison bison) in Canada [13], whitetailed deer (Odocoileus virginianus) in the USA [14, 15], and wild boar (Sus scrofa) in Spain [16, 17]. Many other species, including humans, are susceptible to $M$. bovis but are not believed to sustain transmission in the absence of infection from another species [3] or a change in population or behaviour that enhances disease spread [18]. The host status of a species with regard to $M$. bovis may differ between regions or may change over time depending on population density or management regimen [18]. This, in turn, is the basis for efforts to manage or eradicate M. bovis in wildlife and domestic animals.

Here we present a systematic review of the English scientific literature $(n=163)$ to evaluate the status of M. bovis in free-ranging wildlife of North America. We had three goals: first, to evaluate the known status of M. bovis in wildlife populations of North America; second, to identify potential risks for establishment of M. bovis in uninfected North American wildlife populations where eradication or control would be difficult and costly; and third, to highlight critical issues faced in managing $M$. bovis at the livestock-wildlife interface.

\section{METHODS}

We used a systematic literature review to identify and characterize studies on the status of $M$. bovis in freeranging wildlife populations in North America $[19,20]$. Our review focused on literature published since 1900. All literature relating to the microbiology, epidemiology, or occurrence of $M$. bovis in wildlife were considered eligible and are reflected in the use of the broad search terms: bovine tuberculosis, Mycobacterium bovis, $M$. bovis, and wildlife. The review focused only on the scientific peer-reviewed literature, edited book chapters, and government technical reports in the public domain. We expect that this search will have captured the majority of the scientific publications on M. bovis in the wildlife of North America.

The literature review involved three steps. First, we identified key words for use in the search process. Second, we conducted a systematic review of PubMed, Scopus, and Web of Science according to the search terms. Finally, once all relevant sources were identified and retrieved, we reviewed and categorized each paper. Categories were identified a-priori and included (1) status of M. bovis in wildlife which included case reports, pathology findings, surveillance reports, and molecular epidemiology studies; (2) epidemiology characterization which included analysis of factors associated with transmission or drivers of infection in the wildlife population; (3) mitigation studies evaluating or reporting the use of vaccination development, eradication tools, or other control methods. To identify potential risk factors, studies were reviewed and common themes related to the occurrence of $M$. bovis in free-ranging wildlife were identified. Risk factors identified in each study were enumerated in table format for easy comparison. The frequency with which each risk factor was reported across all studies was assessed and tallied. We report the risk factors most commonly reported in the literature. Due to differing methodologies and often incomplete reporting of results, meta-analysis was not applicable for assessment of risk factors.

\section{RESULTS}

\section{Status of M. bovis infection in North American and Hawaiian wildlife species}

\section{Cervidae}

Historically bTB has been identified and confirmed in nine geographically distinct wildlife populations in North America and Hawaii and is thought to be endemic in three cervid populations (Fig. 1, Table 1). Before the 1990s, M. bovis had only rarely been reported in free-ranging Cervidae in North America. In Canada, Hadwen [21] confirmed M. bovis infection in elk, moose (Alces alces), and mule deer (O. hemionus) that ranged with $M$. bovis-infected bison in the Buffalo National Park in east-central Alberta. Belli [22] reported M. bovis in a white-tailed deer in Ontario, Canada. In the USA, Levine [23] and Friend et al. [24] each reported two cases of $M$. bovis in white-tailed deer in New York, and Ferris et al. [25] reported two cases in white-tailed deer in Illinois. In Michigan, a M. bovis-infected white-tailed deer was documented in 1975 [15] and in Montana, a free-ranging mule deer living near a $M$. bovis-infected elk ranch was diagnosed with $M$. bovis [26].

More recently, hunter harvest surveillance by the Michigan Department of Natural Resources in 1995 identified via bacterial culture an endemic focus of $M$. bovis in free-ranging white-tailed deer within a five-county area of the northeastern Lower Peninsula 


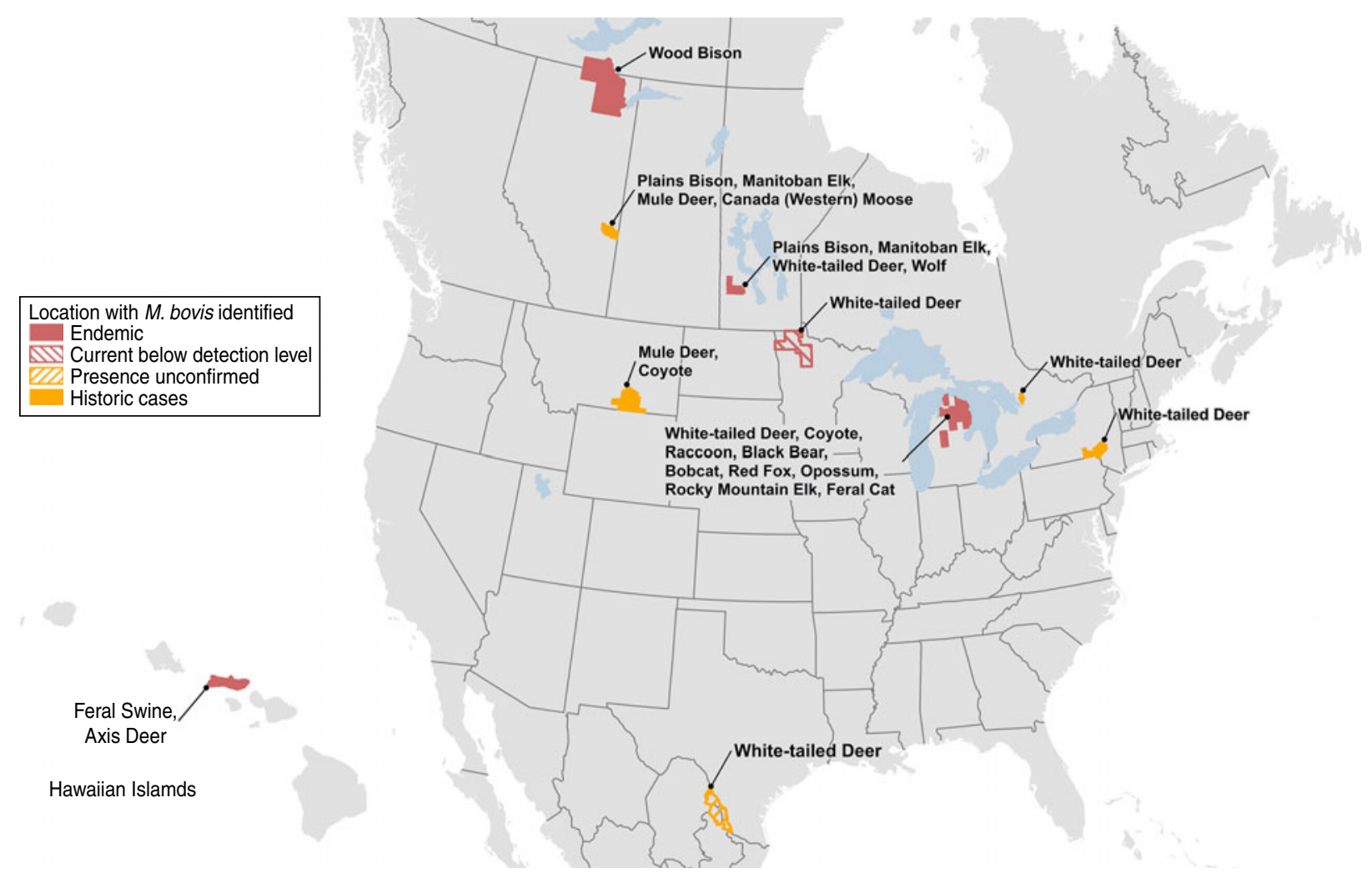

Fig. 1. [colour online]. Reported locations (counties and municipalities) of bovine tuberculosis in North American wildlife.

after $M$. bovis was diagnosed in a hunter-killed white-tailed deer [15, 27-29]. In response, the state established a special deer management unit that encompassed the core area of infected deer. Despite previous reports of $M$. bovis-infected white-tailed deer in New York and Ontario, this focus of infection represented the first known persistent reservoir of M. bovis in white-tailed deer in the North America [9]. It is believed that M. bovis was transmitted from cattle to deer in Michigan sometime during the early to mid-1900s when bTB was widespread in cattle in the state. Epidemiological models estimate that transmission from cattle to deer occurred around 1955 [9].

To manage the epizootic, Michigan adopted two principal management strategies in the affected fivecounty area [14]. First, the state increased hunter harvests to reduce deer population density. Second, it placed restrictions on supplemental feeding and baiting of deer. Voluntary restrictions were initially sought from the public and hunt clubs, followed by a regulatory ban on feeding and baiting within the bTB area and the rest of the state. In addition, Michigan adopted a moratorium on establishing new captive cervid facilities. Hunter harvest has reduced the five-county deer population by about $50 \%$ and, concurrent with these management actions, M. bovis prevalence has declined from $4.9 \%$ to about $1.7 \%$ in adult deer [14, 30]. Rocky Mountain elk (C. canadensis) have also periodically been found to be infected, however at a low apparent prevalence of $0 \cdot 3 \%[31]$.

In 2006, M. bovis was discovered and confirmed using bacterial culture in white-tailed deer in Minnesota in conjunction with an outbreak of M. bovis in beef cattle [32]. One of 474 hunterharvested deer tested in the vicinity of infected cattle herds was positive for $M$. bovis, and targeted culling and surveillance identified another positive deer. Epidemiological linkages between M. bovis-infected deer and cattle were supported by the proximity of deer and cattle cases and $M$. bovis strain identity between cattle and deer. The state responded by initiating more rigorous sampling protocols to estimate prevalence of $M$. bovis in the deer population and conducted widespread culling to reduce deer densities. Hunter-harvested deer surveillance during the autumn hunting season is conducted and if $M$. bovis-infected deer are identified, targeted culling is conducted in the spring around areas where infected deer have 
Table 1. Reported and confirmed cases of Mycobacterium bovis infection in free-ranging wildlife of North America

\begin{tabular}{|c|c|c|c|c|c|}
\hline & Status & $\begin{array}{l}\text { Prevalence } \\
(\%)\end{array}$ & Year & Species & Reference \\
\hline \multicolumn{6}{|l|}{ USA } \\
\hline \multirow[t]{2}{*}{ Hawaii } & Endemic & $<5 \cdot 0$ & $\begin{array}{l}1970,1971,1972 \\
1981,1998\end{array}$ & Axis deer & {$[43,107,108]$} \\
\hline & & $20 \cdot 0-3 \cdot 8$ & 1980, 1994, 1999-present & Feral swine & {$[43,45,108]$} \\
\hline \multirow[t]{9}{*}{ Michigan } & Endemic & $4 \cdot 9-0 \cdot 2$ & 1975, 1994-present & White-tailed deer & {$[14,15,109]$} \\
\hline & & $52-4 \cdot 8$ & $1996-1999 ; 2003-2005$ & Coyote & {$[14,47,48,110]$} \\
\hline & & $4 \cdot 6-2 \cdot 4$ & $1996-2003$ & Raccoon & {$[14,47,110]$} \\
\hline & & $3 \cdot 3-2 \cdot 4$ & 1996-2003 & Black bear & {$[14,47,110]$} \\
\hline & & $12 \cdot 5-7 \cdot 0$ & 1996-2003 & Bobcat & {$[14,47,110]$} \\
\hline & & $16 \cdot 6-10 \cdot 0$ & 1996-2003 & Red fox & {$[14,47,110]$} \\
\hline & & $2 \cdot 4$ & 1996-2003 & Opossum & [14] \\
\hline & & $0 \cdot 3$ & $2000,2001,2003$ & Rocky Mountain elk & [14] \\
\hline & & n.a. & 2000 & Feral cat & [111] \\
\hline Minnesota & Below detection level & $<1 \cdot 2$ & 2005-present & White-tailed deer & {$[32,33,112]$} \\
\hline \multirow[t]{2}{*}{ Montana } & Reported & $4 \cdot 9$ & 1994 & Mule deer & {$[26]$} \\
\hline & & $4 \cdot 3$ & 1994 & Coyote & {$[26]$} \\
\hline New York & Reported & n.a. & $1933,1937,1961$ & White-tailed deer & {$[23,24,113,114]$} \\
\hline \multicolumn{6}{|l|}{ Canada } \\
\hline \multirow[t]{5}{*}{ Alberta } & Endemic & $5 \cdot 5$ & $1939-40$ & Manitoban elk & {$[21,39]$} \\
\hline & & $5 \cdot 6$ & $1939-40$ & Canadian moose & {$[21,39]$} \\
\hline & & $0 \cdot 8$ & $1939-40$ & Mule deer & {$[21,39]$} \\
\hline & & $49 \cdot 0-42 \cdot 0$ & 1925-present & Wood bison & {$[42,115]$} \\
\hline & & $53 \cdot 7$ & $1923-37$ & Plains bison & {$[21,39]$} \\
\hline \multirow[t]{4}{*}{ Manitoba } & Endemic & n.a. & 1937 & Plains bison & {$[75]$} \\
\hline & & n.a. & 1978 & Wolf (pups) & {$[74,116]$} \\
\hline & & $3 \cdot 6-0 \cdot 4$ & $1992,1998-2005$ & Manitoban elk & {$[34,109]$} \\
\hline & & $<0 \cdot 5$ & 1998-2005 & White-tailed deer & {$[34,109]$} \\
\hline Ontario & Reported & $0 \cdot 2$ & 1958 & White-tailed deer & [22] \\
\hline \multicolumn{6}{|l|}{ Mexico* } \\
\hline Tamaulipas & Unconfirmed & $8 \cdot 8$ & 2004-2009 & White-tailed deer & {$[37,38]$} \\
\hline Nuevo León & Unconfirmed & $8 \cdot 5$ & 2004-2009 & White-tailed deer & {$[37,38]$} \\
\hline Coahuila & Unconfirmed & $6 \cdot 0-18 \cdot 7$ & 2004-2009 & White-tailed deer & {$[37,38]$} \\
\hline
\end{tabular}

* Reports for Mexico represent unconfirmed reports only. They are included here for completeness as they are the only reports of M. bovis in wildlife in Mexico. Prevalence reported is for the presence of serum antibodies for bovine purified protein derivative (PPD) and have not been confirmed using bacterial culture.

been found. Based on autumn hunter-harvested sampling, disease prevalence in deer has decreased from $1 \cdot 2 \%$ in 2005 to an undetectable level in 2010 $[32,33]$.

A similar situation exists in Manitoba, Canada, where a herd of 2500-4000 elk (C. c. manitobensis) was implicated in an outbreak of $M$. bovis in 11 cattle herds surrounding Riding Mountain National Park (RMNP) [34]. Commingling of elk and cattle feeding on the same hay bales was considered the most likely mode of transmission between species. Typing of $M$. bovis isolates from this area indicated the presence of a unique strain seemingly unrelated to other strains previously identified in Canada [13, 35]. Management to help reduce transmission of $M$. bovis between wildlife and cattle around RMNP has included increased $M$. bovis surveillance in wildlife and livestock, extended hunting seasons to reduce elk and deer populations, barrier fencing to protect hay-storage yards from free-ranging Cervidae, legislation to prevent baiting and concentration of cervids, and prescribed burning to improve wildlife habitat in RMNP $[13,36]$.

The status of $M$. bovis infection in cervid populations of Mexico is uncertain. Two studies have evaluated the presence of $M$. bovis in free-ranging white-tailed deer in northern Mexico. A serosurvey of white-tailed deer conducted from 2004 to 2009 reported antibody responses to bovine PPD in $8.9 \%$ of deer $(n=347)$ on six ranches in the states of 
Tamaulipas, Nuevo León, and Coahuila [37]. A follow-up study, conducted during the 2009-2010 hunting season, evaluated mandibular lymph nodes and tonsils collected from white-tailed deer for presence of Mycobacterium using histopathology, ZiehlNeelsen staining, mycobacterial isolation and PCR. The study evaluated 44 deer and found that $4.5 \%$ had gross changes. Histopathology revealed morphological changes suggestive of tuberculosis such as macrophage aggregation, necrosis, giant cells, mineralization and bacilli acid-alcohol resistance (BAAR). The presence of $M$. tuberculosis complex by amplification of DNA from a tissue sample by PCR was confirmed. However, M. bovis has not yet been confirmed in white-tailed deer using bacterial culture, which is considered the 'gold standard' for M. bovis identification [38].

\section{Bovidae}

Hadwen [21] documented a severe and prolonged outbreak of M. bovis in bison in Canada's Buffalo National Park (BNP) in Wainwright, Alberta during the early to mid-1900s. The bison herd was maintained in a semi free-ranging condition, within a fenced natural area co-inhabited by elk, deer, and moose. More than one-half of about 12000 bison culled between 1923 and 1939 had M. bovis lesions at meat inspection, as did about $5-6 \%$ of elk and moose and less than $1 \%$ of mule deer culled in 1939 and 1940. Because of the number of source herds for these bison, the exact origin(s) of M. bovis in BNP cannot be stated with any certainty. Possible sources of $M$. bovis infection included domestic cattle that were pastured with bison before the bison were transported to BNP, cattle in areas adjacent to or within the park, or cattle-bison hybrids in one or more of the source herds [13]. BNP was disbanded in 1939 and the herd was destroyed [13].

Canada's largest remaining reservoir of $M$. bovis is the free-ranging bison population in and around Wood Buffalo National Park (WBNP), bordering northern Alberta and southern Northwest Territories. $M$. bovis infection was introduced to the park between 1925 and 1928 when more than 6600 plains bison (B. b. bison) were imported from the infected herd at BNP [3]. The bison population in WBNP grew to an estimated 12000-15000 animals in the late 1940s and then declined to about 5000 by 1968 [39]. Despite a further decline in bison numbers, prevalence of M. bovis has remained high; $39 \%$ of 3400 bison necropsied in the park between 1950 and 1967 had M. bovis lesions [40] and $49 \%$ of 342 bison captured at WBNP between 1997 and 1999 were positive on either the caudal fold test or a fluorescent polarization assay [41]. Tessaro et al. [42] isolated M. bovis from $21 \%$ of 72 bison found in and around WBNP during 1983-1985 and concluded that M. bovis was endemic in the bison population and represented a growing threat to uninfected bison and cattle in the region.

\section{Suidae}

$M$. bovis has not been isolated from feral swine (Sus scrofa) on the mainland of North America; however, it has been isolated from feral swine on Molokai Island, Hawaii [11]. The epidemiological role of feral swine was investigated in a multispecies outbreak of $M$. bovis and although $M$. bovis was efficiently transmitted among swine (estimated prevalence of $20 \%$ ), the disease was controlled in cattle by depopulating infected cattle herds and culling infected swine and deer [43-45]. Post-culling M. bovis prevalence in feral swine was estimated to be $3 \cdot 2 \%$ [45]. More recently feral swine were investigated having been suspected of transmitting $M$. bovis to a cow on the island. Subsequent wildlife surveys for $M$. bovis identified five positive swine out of 482 tested, with an estimated apparent prevalence of $1 \%$ [46]. Risk of transmission to cattle on the island has been mitigated by maintaining cattle in an area of the island where feral swine are not known to exist.

\section{Other species}

There have been relatively few North American surveys for $M$. bovis in host species other than Cervidae and Bovidae. Rhyan et al. [26] reported culture and histopathological evidence of $M$. bovis in 2/16 free-ranging coyotes (Canis latrans) collected adjacent to a confined $M$. bovis-infected elk herd in southwestern Montana. Large-scale investigations of M. bovis infection rates in carnivores were not reported until Bruning-Fann et al. [47] conducted necropsies of 294 carnivores from the M. bovis-endemic area of Michigan. Seven animals had microscopic lesions suggestive of $M$. bovis and nine had lymph node cultures positive for $M$. bovis - six coyotes, two raccoons (Procyon lotor), one red fox (Vulpes vulpes), and one black bear (Ursus americanus). Restriction fragment length polymorphism patterns of $M$. bovis isolates were identical in carnivores and deer, indicating that both groups were infected with the same strain. 
Moreover, most of the lesions in affected carnivores were in mesenteric lymph nodes, suggesting exposure through ingestion of scavenged material. The location of lesions, variety of species involved, and widely dispersed cases of $M$. bovis (i.e. no foci of infection) were indicative of disease spillover (i.e. the incidental infection of a host species that cannot maintain the infection without continued exposure to a competent host) rather than endemic M. bovis in these carnivores [47]. A broader survey of 175 coyotes in Michigan found that $33 \%$ were either culture-positive for M. bovis or had granulomatous lesions suggestive of $M$. bovis infection [48]. Prevalence of $M$. bovis in coyotes varied regionally from $19 \%$ to $52 \%$. Lesions occurred most commonly in the gastrointestinal tract; however, one coyote had advanced disease with lesions occurring in the lung and liver [48]. A study by Johnson et al. [49] found that captive coyotes orally inoculated with $1 \times 10^{5}$ c.f.u. of $M$. bovis did not become infected or shed M. bovis in faeces or oronasally supporting the presumption that coyotes were spillover hosts.

A follow-up study of raccoons in Michigan, reported an estimated apparent prevalence of $2.5 \%$, with 5/199 raccoons testing positive [50]. Another study reported a similar prevalence of $M$. bovis in raccoons, with eight $(2 \cdot 5 \%)$ positive out of 333 sampled [31]. Follow-up investigations documented excretion of $M$. bovis in saliva or nasal secretions in raccoons but not in urine or faeces [51]. Current evidence suggests that raccoons are likely a spillover host for $M$. bovis with no significant role in the maintenance of $M$. bovis in livestock [50,51].

North American opossums (Didelphis virginiana) have also been surveyed with an estimated apparent prevalence of $0 \cdot 5 \%(2 / 379)$ [31] to $3 \cdot 0 \%(4 / 134)$ [50]. Shedding of $M$. bovis has been reported for North American opossums and experimental inoculation has demonstrated that they are relatively susceptible to $M$. bovis infection. However, opossums do not typically develop generalized disease, and therefore, may not shed the bacteria sufficiently to serve as a reservoir for infecting livestock [52, 53].

Avian species may also be involved in the transmission cycle of $M$. bovis, but their relative importance is not well understood [54-56]. In the El Paso Texas milkshed, pigeons (Columba livia), blackbirds (Agelius sp.), and other species were thought to have introduced $M$. bovis into US dairies from dairies in Ciudad Juárez, Mexico, either through mechanical transport of contaminated material or infected birds shedding M. bovis into cattle feed [57]. However, follow-up surveys of tissues from 252 pigeons, nine European starlings (Sturnus vulgaris), and one common grackle (Quiscalus quiscula) from the 14 infected dairies in El Paso failed to identify M. bovis [57]. Blackbirds were not sampled, and the study did not address the potential of birds to mechanically transport M. bovis-contaminated material. Currently, this is the only reported survey of wild avian species for M. bovis in North America.

\section{RISK FACTORS FOR TRANSMISSION OF M. BOVIS TO NORTH AMERICAN WILDLIFE SPECIES}

Four risk factors were consistently and most frequently reported as important to the establishment of $M$. bovis in uninfected wildlife populations in North America: (1) commingling of infected cattle with susceptible wildlife, (2) supplemental feeding of wildlife, (3) inadequate surveillance of at-risk wildlife, and (4) unrecognized emergence of alternate wildlife species as successful maintenance hosts.

\section{Commingling of infected cattle with susceptible wildlife}

Commingling of livestock, particularly cattle, with wildlife has been associated with the introduction of several pathogens into wildlife populations [58, 59]. In North America, examples include Brucella abortus in elk and bison and multiple respiratory pathogens in bighorn sheep [60,61]. In the six wildlife populations in North America - Michigan, Minnesota, Hawaii, RMNP, BNP, and WBNP - known to currently have or historically had endemic $M$. bovis infection, all are thought to have been established via initial transmission of $M$. bovis from cattle to wildlife. In Manitoba, Canada, commingling of elk and cattle feeding on the same hay bales was considered the most likely mode of transmission between species [34].

Commingling of cattle and cervid species is common throughout North America where domestic and wild ruminants share pasture resources. In many regions of North America commingling of cattle with cervid species has increased as wildlife populations have increased [62]. This is expected to continue with growing conservation efforts that preserve valuable wildlife habitat [63]. In some regions of North America, commingling has increased as a result of game ranching which is a rapidly growing segment of the US animal agriculture industry, particularly in 

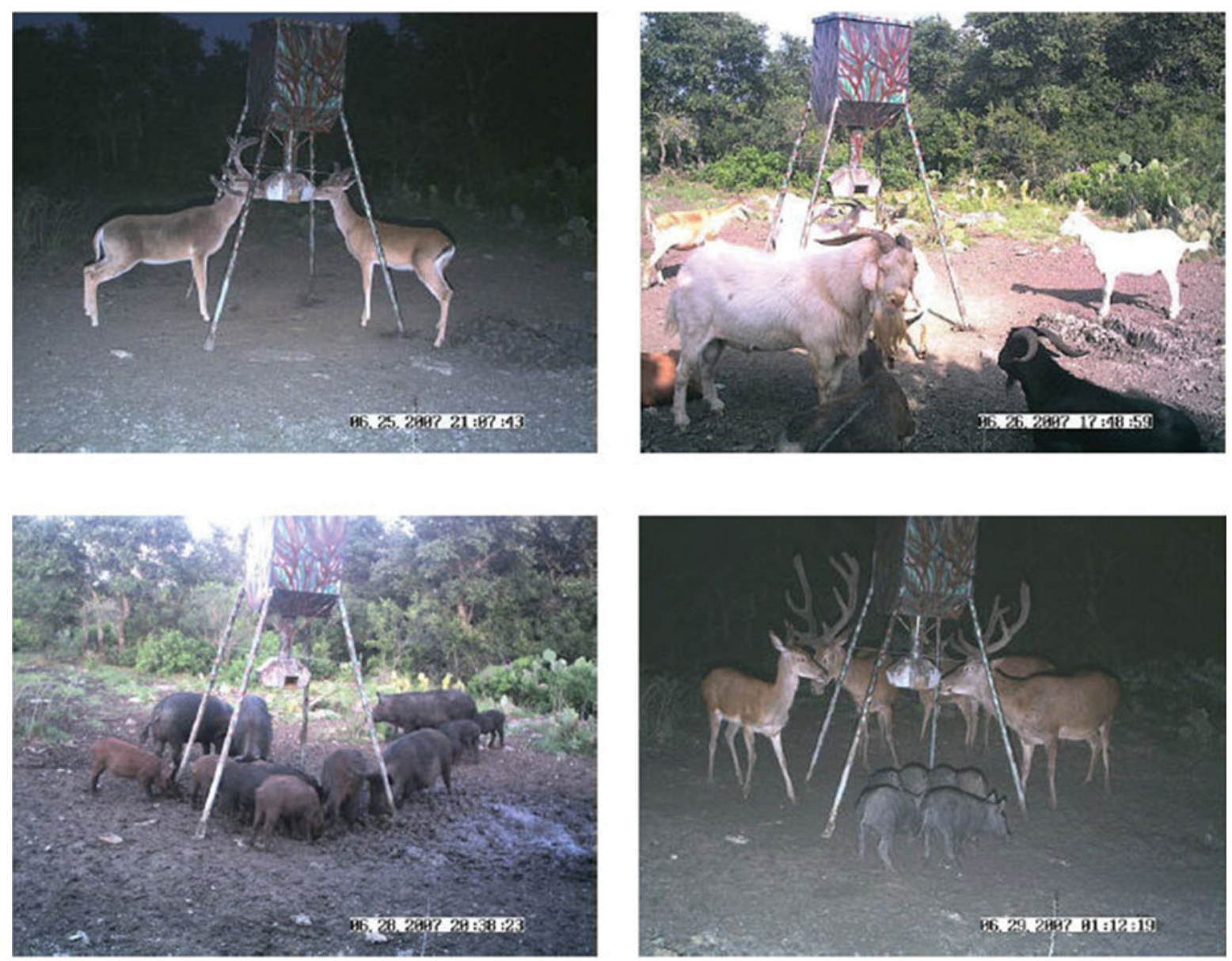

Fig. 2. [colour online]. Examples of livestock and wildlife use of a protein feeder in South Texas.

parts of the South and Midwestern United States [64]. This often controversial industry is thought by some to pose a risk for introducing and establishing additional foci of endemic wildlife diseases, including M. bovis [65]. In some locations, exotic hoofstock or native Cervidae are released or baited into a semi free-ranging environment for recreational hunting. There, the animals often mix with cattle and feral swine (Fig. 2), creating an environment for pathogen exchange [66]. Some livestock producers have boosted incomes by combining exotic and native hoofstock game ranching with traditional cattle production; others have replaced cattle with exotic or native hoofstock ranching as a new form of animal agriculture.

\section{Supplemental feeding of wildlife}

Research indicates that supplemental feeding and baiting have been major factors in the propagation and persistence of $M$. bovis in Michigan's white-tailed deer population [14]. Deer populations with the highest prevalence of $M$. bovis were clustered on private land where feeding and baiting were common practices. M. bovis can survive for months on foodstuffs commonly used by deer [14] and transmission between deer via shared feed has been documented [67]. Shared feed also appears to be the primary route of $M$. bovis transmission from deer to cattle $[14,67]$. Furthermore in Michigan the presence of supplemental feeding has been identified as a significant predictor of $M$. bovis prevalence in white-tailed deer [68]. Deer density, which is often increased by supplemental feeding, has also been associated with increased prevalence of $M$. bovis [14]. Collectively these data strongly suggest that supplemental feeding and baiting of deer has been a critical factor in the persistence of M. bovis in Michigan's deer population [14]. States that employ this practice would also be at risk if $M$. bovis were introduced [15, 67-69]. Recreational feeding of wildlife for viewing or hunting is common throughout North America and has been banned or restricted in only 16 states. The remaining 
states have few or no regulations regarding feeding of wildlife.

The federal and state feeding grounds in Wyoming, where brucellosis is an ongoing problem in elk, are a particular worry with regard to the spread of wildlife diseases $[58,59]$ including $M$. bovis [70]. Winter feeding of elk in Wyoming has a long history. The first feedground, the federally operated National Elk Refuge, was created in 1912 to mitigate damage to hay stored for wintering cattle. Over the past century the number of feeding grounds has grown in Wyoming; the state now manages 22 feedgrounds in three counties. On average, these sites support 20500 elk comprising an estimated $80 \%$ of the state's total elk population during winter [71-73]. Despite increasing recognition of wildlife disease risks, social and political constraints have allowed for the continued operation of the winter feedgrounds in Wyoming [73]. Several other western states also periodically feed populations of elk, deer, and bighorn sheep during severe winters when animal mortality is expected to be high [73]. Although less of a hazard due to the infrequent nature of these feeding programmes, these practices also pose a risk of spreading of $M$. bovis, if it were introduced.

\section{Inadequate surveillance of at-risk wildlife}

There is evidence that $M$. bovis infections in freeranging wildlife may be silent, existing for years or even decades before being detected in hunter-killed animals or emerging or re-emerging in local cattle populations. Examples include Michigan, where M. bovis is thought to have persisted for $40-50$ years before identification, Hawaii's Molokai Island, where M. bovis persisted for years among feral swine before being identified in cattle, and RMNP where bTB was first identified in 1937 but re-emerged in cattle and elk in 1991 more than 50 years after first being discovered in wildlife [74, 75]. Lack of surveillance, poor diagnostic tests, and the extended latency of M. bovis pose risks for re-emergence of this pathogen in areas where it has historically existed in wildlife or cattle.

In addition there is likely to be bias associated with historic accounts of $M$. bovis in wildlife. Wobeser [13] discussed the scarcity of documented bTB cases in wild Cervidae in North America during the early to mid-1900s suggesting several factors that may have contributed to the lack of such reports, including the fact that deer were less abundant $40-50$ years ago, disease surveillance in wildlife was not a routine practice, and $M$. bovis lesions in Cervidae may not have been recognized as tuberculosis. The few early cases of $M$. bovis in cervids in North America were regarded as spillover events from cattle, in which $M$. bovis was quite common at the time. The potential for $M$. bovis infections in free-ranging wildlife to exist undetected for years or even decades necessitates robust surveillance systems in wildlife, particularly in regions where M. bovis has been historically identified. In addition, surveillance around $M$. bovis-infected cattle herds is needed to identify and address infection in wildlife.

\section{Alternate wildlife species as maintenance hosts}

Traditionally, it was assumed that $M$. bovis would not persist in populations of free-ranging deer or elk unless they had contact with infected bison, cattle herds, or captive deer $[44,76]$. This initial presumption that affected wildlife cannot successfully maintain $M$. bovis in the population has been a consistent theme associated with nearly all of the established wildlife reservoirs in North America. As a result animal health authorities have often limited surveillance in potentially affected wildlife or disregarded findings of $M$. bovis in wildlife. This may contribute as a risk factor for wildlife species that are currently considered to be purely spillover species and thought unable to maintain persistent infection in the population. In contrast to this paradigm Minnesota presumed that deer could become a wildlife reservoir and aggressively reduced the deer population in the affected area by $55 \%$ and banned recreational feeding [33]. Currently $M$. bovis infection in the affected area has declined to undetectable levels.

Feral swine may pose a significant risk for spread of M. bovis. Historically, feral swine were considered spillover hosts, unable to maintain infection at the population level [77, 78]. However scientific evidence regarding the role of feral swine in the epidemiology of $M$. bovis is shifting this view. Naranjo et al. [16] reported that wild boar in Mediterranean ecosystems sustained $M$. bovis infection and appeared capable of transmitting the disease to other species. Supporting evidence included high prevalence of $M$. bovis in wild boar fenced from contact with other species, lesions in thoracic lymph nodes and lungs suggesting respiratory infection and transmission, and extensive lesions in juvenile boar that likely represented the main shedders of $M$. bovis. Likewise, Aranaz et al. [79], de Mendoza et al. [80], and Santos et al. [81] concluded that wild boar in Spain and Portugal were 


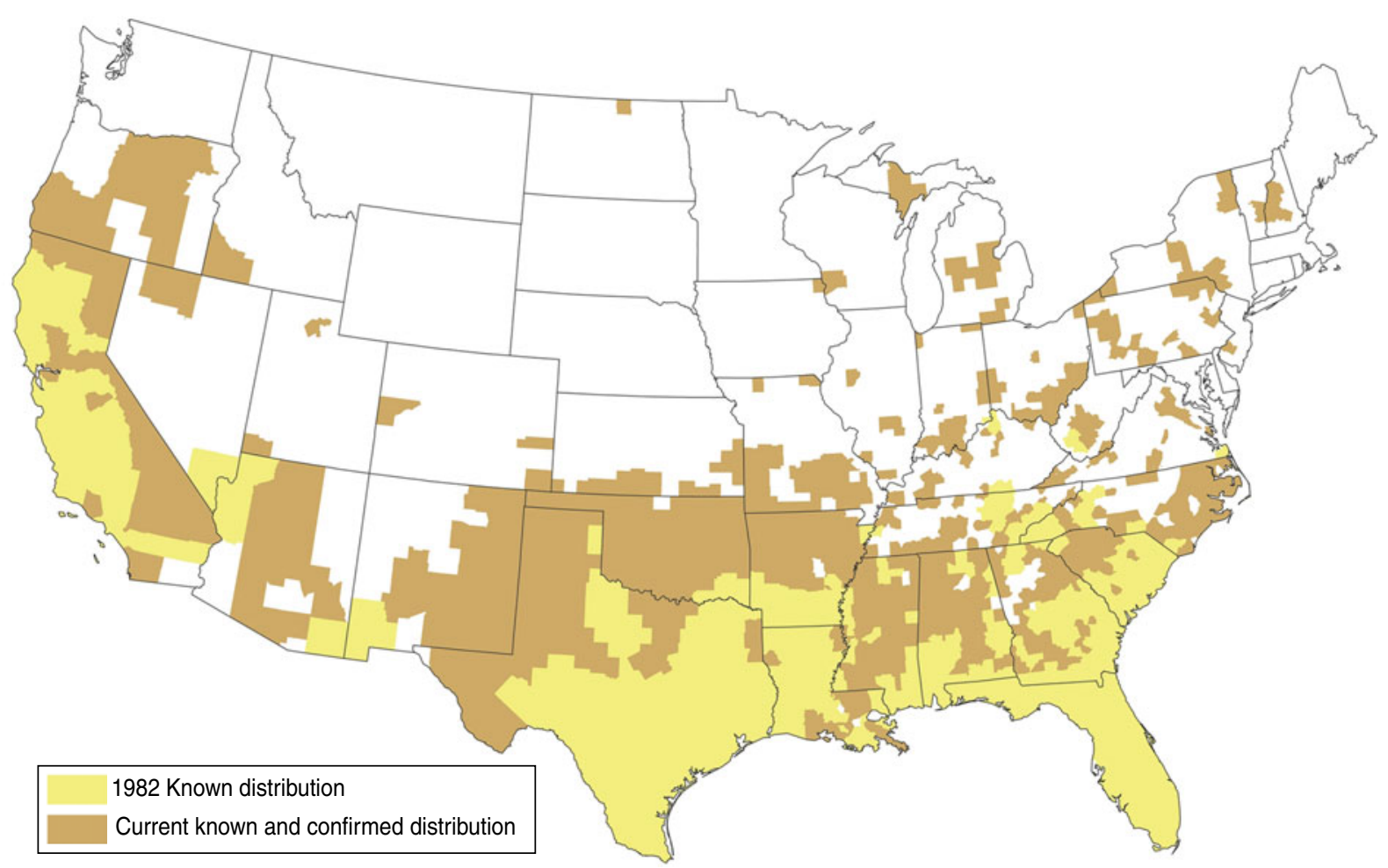

Fig. 3. [colour online]. Current known range of feral swine in the USA. Sources include data from APHIS Wildlife Services National Wildlife Disease and Emergency Response Program, the Southeastern Cooperative Wildlife Disease Study, and APHIS Veterinary Services Feral Swine Tracking and Monitoring Data.

maintenance hosts of $M$. bovis based on ecological factors and lesion characteristics. Circumstances favouring M. bovis transmission between wildlife and livestock included artificial increases in wild game populations stimulated by a robust hunting industry, lack of natural predators, and intensive cattle grazing in game preserves with susceptible wildlife hosts [80].

Given the range expansion of feral swine in North America (Fig. 3) there is enormous concern over their capacity for transmitting diseases that impact animal agriculture and human health. Free-ranging populations of swine have been reported in at least 38 US states and three Canadian provinces, nearly doubling the number of states occupied since 1988 [82]. Particularly worrisome is the recent appearance of feral swine in Michigan, where the potential exists for interaction with $M$. bovis-infected white-tailed deer and cattle.

\section{OPPORTUNITIES FOR MANAGEMENT OF M. BOVIS IN WILDLIFE}

The need for a structured approach to management of diseases shared between wildlife and livestock has been identified as a critical need in North America
(1). Concepts for integrated adaptive management of diseases at the livestock-wildlife interface have been proposed by multiple authors [1, 83, 84]. Furthermore, many countries have developed surveillance systems for disease events in wildlife [85]. Many of these systems implement integrated adaptive disease management using risk assessments and disease monitoring systems for wildlife [86-89]. These systems have common themes, which may be adaptable to the management of M. bovis in North America. Disease management systems that integrate methods to identify newly emerging science related to $M$. bovis conduct risk evaluations of wildlife, implement risk mitigations to prevent transmission between cattle and wildlife, and conduct disease surveillance in at-risk wildlife, would be the most successful at preventing new foci of $M$. bovis infection in wildlife [1]. Integrating these components allows adaptive management of the disease system and may provide the most success for management of M. bovis. Adaptive management has been well described in the ecological and wildlife management literature [90, 91], but has only recently been proposed as a method for managing disease systems [1, 83, 84].

Rapid identification of emerging science of $M$. bovis in wildlife is critical to successful management and 
prevention of additional foci of infection in North America. Even well-documented disease systems, such as bTB, can rapidly change with new issues emerging. Furthermore, policies to address the newly emerging science are often slowly adopted, detrimentally influencing agricultural systems and wildlife management in North America [61, 92]. Risk analysis can then be used to understand risks posed these emerging issues [93]. However, for diseases at the livestock-wildlife interface, quantitative risk assessments are often limited by the availability of data describing contact between wildlife and livestock. Historically, risk assessments have often assessed the risk of pathogen transmission from wildlife to livestock [94]. However, for M. bovis in North America the initial transmission event is often from livestock to wildlife $[95,96]$. The most successful and useful risk analyses for $M$. bovis should consider the bi-directional nature of transmission. This then allows for the implementation of risk mitigations to prevent transmission between livestock and wildlife.

Mitigating risks of pathogen transmission between livestock and wildlife has received considerable attention [83, 97, 98]. The ability to eliminate $M$. bovis from North American wildlife populations has been rare and when successful required extensive culling of wildlife. The only example of success is the likely eradication of bTB from Minnesota where over 9700 deer were tested and the deer population in the affected area was reduced by an estimated $55 \%$ in 4 years $[33,99]$. This effort cost an estimated US $\$ 86$ million in federal and state government expenditures [33].

Wildlife removal strategies can have unintended consequences, as exemplified in the UK where badger behaviour was changed as a result of culling, increasing the risk of $M$. bovis transmission to cattle [100]. Eradication efforts requiring culling of large numbers of wildlife are costly and often publicly untenable, thus preventing establishment of $M$. bovis in wildlife populations is a central pillar of long-term risk mitigation strategies [101]. Implementing risk mitigations that integrate wildlife surveillance, modify livestock husbandry practices, incorporate barriers between livestock and wildlife, and use other wildlife deterrents may offer the greatest potential for reducing economic and social impacts resulting from newly infected wildlife populations [97, 98, 102].

The need to develop comprehensive surveillance systems that integrate livestock and wildlife components has been suggested $[1,103]$. Robust surveillance systems in wildlife at the livestock-wildlife interface to provide early detection of $M$. bovis when transmission from livestock to wildlife occurs is essential. Recent epidemiological models suggest that once $M$. bovis is introduced, the probability of becoming established in a wildlife population is at least $10 \%$ [104]. Furthermore, once established M. bovis can be fiscally impossible to eradicate, recent analysis found that to achieve eradication in Michigan would cost at least US \$1.5 million annually over the next 30 years [105]. As a result identification and rapid response when $M$. bovis is transmitted from livestock to wildlife has proven the most successful tool for preventing establishment of $M$. bovis in wildlife [33]. Early detection in an outbreak is essential for successful control of the pathogen; however, this requires proactive testing of wildlife by animal health authorities. Furthermore, surveillance of potentially affected wildlife must be done at levels necessary to identify $M$. bovis in the susceptible wildlife population.

Surveillance should include species known to be at risk for maintaining $M$. bovis (i.e. white-tailed deer, elk, bison) and also species that have been identified as potential emerging maintenance hosts such as freeranging swine. Creative surveillance programmes that sample both known maintenance species and use sentinel species (e.g. coyotes) may provide the best solution for conducting surveillance at detection levels while balancing what is fiscally feasible [48, 106]. Developing a comprehensive national monitoring system for $M$. bovis in wildlife that is logistically and fiscally sustainable could yield economic benefits for livestock health management by helping prevent transmission from livestock to wildlife through early detection.

\section{CONCLUSION}

M. bovis has been identified in nine geographically distinct wildlife populations in North America and is endemic in at least three of these populations. Furthermore, the status of $M$. bovis in an additional cervid population in Northern Mexico is uncertain requiring additional investigation. A structured approach to management is needed to prevent the establishment of $M$. bovis in additional susceptible wildlife populations. Theoretical and practical methods for integrated adaptive wildlife disease management have been proposed by multiple authors $[1,83,84]$. Integration of these concepts to directly address critical risk factors associated with establishment of $M$. bovis in wildlife offers the best opportunity to successfully manage this pathogen in North 
American wildlife. Adaptive disease management principles can help integrate and prioritize surveillance activities along with the development and deployment of effective, practical, and economical mitigation measures designed to lower bTB transmission risk. Furthermore, control tools such as intensive culling or hunting, specifically for reducing disease transmission, can be incorporated when appropriate in the adaptive management framework. This would allow for incorporation of uncertainty such as the limited understanding of the effect culling might have on deer populations and the dynamics of M. bovis infection in these populations. Strategies such as selective culling of high-risk individuals or groups can be tested as part of the management process to improve the development of practical and effective culling programmes.

\section{ACKNOWLEDGEMENTS}

We appreciate the encouragement of $\mathrm{Dr}$ Katie Portacci and Dr Jerry Freier. We thank Dr Kurt VerCauteren, Dr Mike Dunbar, Dr Thomas Gidlewski, Dr Colleen Bruning-Fann, and Dr Thomas Kasari for detailed review of our work and providing suggestions. We also thank numerous other reviewers for their thoughts on the manuscript.

\section{DECLARATION OF INTEREST}

None.

\section{REFERENCES}

1. Miller RS, Farnsworth ML, Malmberg JL. Diseases at the livestock-wildlife interface: status, challenges, and opportunities in the United States. Preventive Veterinary Medicine (in press).

2. Sweeney SJ, Miller RS. Free-ranging wildlife. In: Portacci K, Lombard J, eds. Assessment of Pathways for the Introduction and Spread of Mycobacterium bovis in the United States. Fort Collins, Colorado: United States Department of Agriculture, Animal Plant Health Inspections Service, 2010, 144 pp.

3. O'Reilly LM, Daborn CJ. The epidemiology of Mycobacterium bovis infections in animals and man: a review. Tubercle and Lung Disease 1995; 76 (Suppl. 1): $1-46$.

4. Cheeseman CL, Wilesmith JW, Stuart FA. Tuberculosis: the disease and its epidemiology in the badger, a review. Epidemiology and Infection 1989; 103: 113-125.

5. Delahay RJ, et al. The spatio-temporal distribution of Mycobacterium bovis (bovine tuberculosis) infection in a high-density badger population. Journal of Animal Ecology 2001; 69: 428-441.
6. Noonan NL, et al. Wildlife as a possible reservoir of bovine tuberculosis. Irish Veterinary Journal 1975; 29: 1.

7. Woodroffe R, et al. Spatial association of Mycobacterium bovis infection in cattle and badgers Meles meles. Journal of Applied Ecology 2005; 42: 852-862.

8. Morris RS, Pfeiffer DU. Directions and issues in bovine tuberculosis epidemiology and control in New Zealand. New Zealand Veterinary Journal 1995; 43: 256-265.

9. Palmer MV. Tuberculosis: a reemerging disease at the interface of domestic animals and wildlife. In: Childs JE, Mackenzie JS, Richt JA, eds. Wildlife and Emerging Zoonotic Diseases: The Biology, Circumstances and Consequences of Cross-Species Transmission. New York: Springer, 2007, pp. 195-215.

10. Bengis RG, et al. An outbreak of bovine tuberculosis in a free-living African buffalo (Syncerus caffer Sparrman) population in the Kruger National Park: a preliminary report. Onderstepoort Journal of Veterinary Research 1996; 63: 15.

11. De Lisle GW, Mackintosh CG, Bengis RG. Mycobacterium bovis in free-living and captive wildlife, including farmed deer. Revue Scientifique et Technique de l'Office International des Épizooties 2001; 20: 86-111.

12. De Vos V, et al. The epidemiology of tuberculosis in free ranging African buffalo (Syncerus caffer) in the Kruger National Park, South Africa. Onderstepoort Journal of Veterinary Research 2001; 68: 119-130.

13. Wobeser G. Bovine tuberculosis in Canadian wildlife: an updated history. Canadian Veterinary Journal 2009; 50: $1169-1176$.

14. O'Brien DJ, et al. Managing the wildlife reservoir of Mycobacterium bovis: the Michigan, USA, experience. Veterinary Microbiology 2006; 112: 313-323.

15. Schmitt SM, et al. Bovine tuberculosis in free-ranging white-tailed deer from Michigan. Journal of Wildlife Diseases 1997; 33: 749-758.

16. Naranjo V, et al. Evidence of the role of European wild boar as a reservoir of Mycobacterium tuberculosis complex. Veterinary Microbiology 2008; 127: 1-9.

17. Parra A, et al. An epidemiological evaluation of Mycobacterium bovis infections in wild game animals of the Spanish Mediterranean ecosystem. Research in Veterinary Science 2006; 80: 140-146.

18. Cousins DV, Florisson N. A review of tests available for use in the diagnosis of tuberculosis in non-bovine species. Revue Scientifique et Technique de l'Office des International des Épizooties 2005; 24: 1039-59.

19. Khan KS, et al. Five steps to conducting a systematic review. Journal of the Royal Society of Medicine 2003; 96: $118-121$.

20. Okoli C. A critical realist guide to developing theory with systematic literature reviews. Social Science Research Network, 2012.

21. Hadwen S. Tuberculosis in the buffalo. Journal of the American Veterinary Medical Association 1942; 100: 19 22.

22. Belli LB. Bovine tuberculosis in white-tailed deer (Odocoileus virginianus). Canadian Veterinary Journal 1962; 3: 356-358. 
23. Levine PP. A report on tuberculosis in wild deer (Odocoileus virginianus). Cornell Veterinarian 1934; 24 : 264-266.

24. Friend M, Kroll ET, Gruft H. Tuberculosis in a whitetailed deer. New York Fish and Game Journal 1963; 10: $118-123$.

25. Ferris DH, et al. Tuberculosis in transported deer. Journal of the American Veterinary Medical Association 1961; 138: 326-328.

26. Rhyan JC, et al. Bovine tuberculosis in a free-ranging mule deer (Odocoileus hemionus) from Montana. Journal of Wildlife Disease 1995; 31: 432-435.

27. O'Brien DJ, et al. Tuberculous lesions in free-ranging white-tailed deer in Michigan. Journal of Wildlife Diseases 2001; 37: 608-613.

28. O'Brien DJ, et al. Epidemiology of Mycobacterium bovis in free-ranging white-tailed deer, Michigan, USA, 1995-2000. Preventive Veterinary Medicine 2002; 54: 47-63.

29. Palmer MV, et al. Tonsillar lesions in white-tailed deer (Odocoileus virginianus) naturally infected with Mycobacterium bovis. Veterinary Record 2002; 151: 149.

30. O'Brien DJ, et al. Management of bovine tuberculosis in Michigan wildlife: current status and near term prospects. Veterinary Microbiology 2011; 151: 179-187.

31. O'Brien DJ, et al. Managing the wildlife reservoir of Mycobacterium bovis: the Michigan, USA, experience. Veterinary Microbiology 2006; 112 (Special Issue): 313-23.

32. Portacci KA, et al. Assessment of risk associated with the Minnesota proposed plan for split-state status for Mycobacterium bovis (bovine tuberculosis). United States Department of Agriculture, Animal Plant Health Inspection Service, 2008, p. 121.

33. Carstensen M, DonCarlos MW. Preventing the establishment of a wildlife disease reservoir: a case study of bovine tuberculosis in wild deer in Minnesota, USA. Veterinary Medicine International 2011; 2011: 10 .

34. Lees VW, Copeland S, Rousseau P. Bovine tuberculosis in elk (Cervus elaphus manitobensis) near Riding Mountain National Park, Manitoba, from 1992 to 2002. Canadian Veterinary Journal 2003; 44: 830-831.

35. Lutze-Wallace C, et al. Spoligotyping of Mycobacterium bovis isolates found in Manitoba. Canadian Journal of Veterinary Research 2005; 69: 143-5.

36. Nishi JS, Shury T, Elkin BT. Wildlife reservoirs for bovine tuberculosis Mycobacterium bovis) in Canada: strategies for management and research. Veterinary Microbiology 2006; 112: 325-338.

37. Medrano C, et al. Zoonotic pathogens among whitetailed deer, Northern Mexico, 2004-2009. Emerging Infectious Diseases 2012; 18: 1372.

38. Barrios-García H, et al. Identification of Mycobacterium tuberculosis complex by histopathology and PCR in white-tailed deer (Odocoileus virginianus) in Tamaulipas, Mexico. Journal of Animal and Veterinary Advances 2012; 11: 1036-1040.
39. Tessaro SV. The existing and potential importance of brucellosis and tuberculosis in Canadian wildlife: a review. Canadian Veterinary Journal 1986; 27: 119-124.

40. Broughton E. Diseases affecting bison. In: Reynolds HW, Hawley AWL, eds. Bison Ecology in Relation to Agricultural Development in the Slave River Lowlands, NWT. Ontario, Canada. Canadian Wildlife Service, Ottawa, 1987, pp. 34-38.

41. Jolley ME, et al. Fluorescence polarization assay for the detection of antibodies to Mycobacterium bovis in bovine sera. Veterinary Microbiology 2007; 120: 113 121.

42. Tessaro SV, Forbes LB, Turcotte C. A survey of brucellosis and tuberculosis in bison in and around Wood Buffalo National Park, Canada. Canadian Veterinary Journal 1990; 31: 174-180.

43. Essey MA, et al. Bovine tuberculosis surveys of axis deer and feral swine on the Hawaiian island of Molokai. In: Proceedings of the US Animal Health Association, 1981, pp. 538-549.

44. Essey MA, Vantiem JS. Mycobacterium bovis infection in captive Cervidae: an eradication program. In: Thoen CO, Steele JH, eds. Mycobacterium bovis Infection in Animals and Humans. Ames, IA: Iowa State University Press, 1995, pp. 145-157.

45. Essey MA, et al. Follow up survey of feral swine for Mycobacterium bovis infection on the Hawaiian island of Molokai. In: Proceedings of the US Animal Health Association, 1983, pp. 589-595.

46. Anon. Risk assessment transmission of bovine tuberculosis (Mycobacterium bovis) from feral swine to cattle on the island of Molokai. Fort Collins, Colorado: United States Department of Agriculture, Animal Plant Health Inspection Service, 2006.

47. Bruning-Fann CS, et al. Bovine tuberculosis in freeranging carnivores from Michigan. Journal of Wildlife Diseases 2001; 37: 58-64.

48. VerCauteren KC, et al. Surveillance of coyotes to detect bovine tuberculosis, Michigan. Emerging Infectious Diseases 2008; 14: 1862-1869.

49. Johnson SR, et al. Experimental inoculation of coyotes with Mycobacterium bovis: susceptibility and shedding. In: Proceedings of the US Animal Health Association, 2009, pp. 94-97.

50. Witmer G, et al. Epizootiologic survey of Mycobacterium bovis in wildlife and farm environments in northern Michigan. Journal of Wildlife Diseases 2010; 46 368-378.

51. Palmer MV, Waters WR, Whipple DL. Susceptibility of raccoons (Procyon lotor) to infection with Mycobacterium bovis. Journal of Wildlife Diseases 2002; 38: 266-274.

52. Fitzgerald SD, et al. Experimental aerosol inoculation of Mycobacterium bovis in North American opossums (Didelphis virginiana). Journal of Wildlife Diseases 2003; 39: 418-423.

53. Diegel KLF et al. Experimental inoculation of North American opossums (Didelphis virginiana) with Mycobacterium bovis. Journal of Wildlife Diseases 2002; 38 275-281. 
54. Butler KL, et al. Experimental inoculation of European starlings (Sturnus vulgaris) and American crows (Corvus brachyrhynchos) with Mycobacterium bovis. Avian Diseases 2001; 45: 709-718.

55. Clark L, McLean RG. A review of pathogens of agricultural and human health interest found in blackbirds. In: Linz GM, ed. Proceedings of Symposium on Management of North American Blackbirds. U.S. Department of Agriculture, Animal and Plant Health Inspection Service, Wildlife Services, National Wildlife Research Center, Fort Collins, Colorado, 2003, pp. 103-108.

56. Clarke KR, et al. Experimental inoculation of wild turkeys (Meleagris gallopavo) with Mycobacterium bovis. Avian Diseases 2006; 50: 131-134.

57. Pillai SD, et al. Failure to identify non-bovine reservoirs of Mycobacterium bovis in a region with a history of infected dairy-cattle herds. Preventive Veterinary Medicine 2000; 43: 53-62.

58. Cross PC, et al. Effects of management and climate on elk brucellosis in the Greater Yellowstone ecosystem. Ecological Applications 2007; 17: 957-964.

59. Maichak EJ, et al. Effects of management, behavior, and scavenging on risk of brucellosis transmission in elk of western Wyoming. Journal of Wildlife Diseases 2009; 45: 398-410.

60. Wolfe LL, et al. A bighorn sheep die-off in southern Colorado involving a Pasteurellaceae strain that may have originated from syntopic cattle. Journal of Wildlife Diseases 2010; 46: 1262-1268.

61. Olsen S. Brucellosis in the United States: role and significance of wildlife reservoirs. Vaccine 2010; 28: F73-F6.

62. Côté SD, et al. Ecological impacts of deer overabundance. Annual Review of Ecology, Evolution, and Systematics 2004, pp. 113-147.

63. Rooney TP. Deer impacts on forest ecosystems: a North American perspective. Forestry 2001; 74: 201208.

64. Teer J, Renecker L, Hudson R. Non-native large ungulates in North America. Wildlife production: conservation and sustainable development Fairbanks, Alaska: Agricultural and Forestry Experiment Station, University of Alaska 1991, pp. 55-66.

65. Butler MJ, et al. Wildlife ranching in North Americaarguments, issues, and perspectives. Wildlife Society Bulletin 2005; 33: 381-389.

66. Cooper SM, et al. Distribution and interspecies contact of feral swine and cattle on rangelands in South Texas: implications for disease transmission. Journal of Wildlife Diseases 2010; 46: 152-164.

67. Palmer MV, Waters WR, Whipple DL. Investigation of the transmission of Mycobacterium bovis from deer to cattle through indirect contact. American Journal of Veterinary Research 2004; 65: 1483-1489.

68. Hickling GJ. Dynamics of bovine tuberculosis in wild white-tailed deer in Michigan. Lansing, Michigan, USA: Michigan Department of Natural Resources, 2002; Wildlife Division Report Number 3363, pp. 34.

69. Miller R, et al. Evaluation of the influence of supplemental feeding of white-tailed deer (Odocoileus virginianus) on the prevalence of bovine tuberculosis in the Michigan wild deer population. Journal of Wildlife Diseases 2003; 39: 84-95.

70. Peterson MJ. Infectious agents of concern for the Jackson Hole elk and bison herds: an ecological perspective. College Station, Texas, USA: Department of Wildlife and Fisheries Sciences, Texas A\&M University, 2003.

71. Boyce MS. The Jackson Elk Herd: Intensive Wildlife Management in North America. Cambridge, England: Cambridge University Press, 1989, pp. 306.

72. Dean R, et al. Elk feedgrounds in Wyoming. Wyoming Game and Fish Department (unpublished report). Cheyenne, Wyoming, USA, 2004.

73. Smith BL. Winter feeding of elk in western North America. Journal of Wildlife Management 2001; 65: 173-190.

74. Carbyn LN. Incidence of disease and its potential role in the population dynamics of wolves in Riding Mountain National Park, Manitoba. In: Harrington FH, Paquet C, eds. Wolves of the World: Perspectives of Behavior, Ecology and Conservation. New Jersey: Noyes Publications, 1982, pp. 106-116.

75. Tabulenas DT. A narrative human history of Riding Mountain National Park and area: prehistory to 1980. Winnipeg, Canada: Parks Canada, 1983.

76. Bleem AM, et al. Overview of the assessment of risk factors for Mycobacterium bovis in the United States. Animal Health Insight 1993, Summer, pp. 10-21.

77. Corner LAL. The role of wild animal populations in the epidemiology of tuberculosis in domestic animals: how to assess the risk. Veterinary Microbiology 2006; 112: 303-12.

78. McInerney JP, Small KJ, Caley P. Prevalence of $\mathrm{Myco}$ bacterium bovis infection in feral pigs in the Northern Territory. Australian Veterinary Journal 2008; 72: 448-451.

79. Aranaz A, et al. Bovine tuberculosis (Mycobacterium bovis) in wildlife in Spain. Journal of Clinical Microbiology 2004; 42: 2602-2608.

80. de Mendoza JH, et al. Bovine tuberculosis in wild boar (Sus scrofa), red deer (Cervus elaphus) and cattle (Bos taurus) in a Mediterranean ecosystem (1992-2004). Preventive Veterinary Medicine 2006; 74: 239-247.

81. Santos N, et al. Epidemiology of Mycobacterium bovis infection in wild boar (Sus scrofa) from Portugal. Journal of Wildlife Diseases 2009; 45: 1048-1061.

82. Hutton T, et al. Disease risks associated with increasing feral swine numbers and distribution in the United States. Rhinelander, Wisconsin: Midwest Association of Fish and Wildlife Agencies, Wildlife and Fish Health Commission, 2006, p. 15.

83. Wasserberg G, et al. Host culling as an adaptive management tool for chronic wasting disease in white tailed deer: a modelling study. Journal of Applied Ecology 2009; 46: 457-466.

84. Thirgood S. New perspectives on managing wildlife diseases. Journal of Applied Ecology 2009; 46: 454- 456.

85. Morner T, et al. Surveillance and monitoring of wildlife diseases. Revue Scientifique et Technique de l'Office International des Épizooties 2002; 21: 67-76. 
86. Hartley M, Gill E. Assessment and mitigation processes for disease risks associated with wildlife management and conservation interventions. Veterinary Record 2010; 166: 487-490.

87. Hartley M, Lysons R. Development of the England Wildlife Health Strategy - a framework for decision makers. Veterinary Record 2011; 168: 158-164.

88. Lysons R, Gibbens J, Smith L. Progress with enhancing veterinary surveillance in the United Kingdom. Veterinary Record 2007; 160: 105-12.

89. Sainsbury A, et al. Status of wildlife health monitoring in the United Kingdom. Veterinary Record 2001; 148: $558-563$.

90. Kendall WL. Using models to facilitate complex decisions. In: Modeling in Natural Resource Management. Washington, DC: Island Press, 2001, pp. 147-170.

91. McCarthy MA, Possingham HP. Active adaptive management for conservation. Conservation Biology 2007; 21: 956-963.

92. O'Brien DJ, et al. Management of bovine tuberculosis in Michigan wildlife: current status and near term prospects. Veterinary Microbiology 2011; 151: 179-87.

93. Suter GW. Ecological Risk Assessment, 2nd edn. Boca Raton, FL: CRC Press, 2007, pp. 643.

94. Daniels M, Hutchings M, Greig A. The risk of disease transmission to livestock posed by contamination of farm stored feed by wildlife excreta. Epidemiology and Infection 2003; 130: 561-568.

95. Tessaro SV. The existing and potential importance of brucellosis and tuberculosis in Canadian Wildlife: a review. Canadian Veternary Journal 1986; 27: 119-122.

96. Sweeney SJ, Miller RS. Free-ranging wildlife. In: Portacci K, Lombard J, eds. Assessment of Pathways for the Introduction and Spread of Mycobacterium bovis in the United States. Fort Collins, Colorado: United States Department of Agriculture, Animal Plant Health Inspections Service, 2010, pp. 94-123.

97. VerCauteren K, Gehring T, Landry J. The dynamic role of livestock protection dogs in a changing world. Journal of Veterinary Behavior: Clinical Applications and Research 2010; 6: 73-74.

98. VerCauteren K, Lavelle M, Hygnstrom S. Fences and deer-damage management: a review of designs and efficacy. Wildlife Society Bulletin 2006; 34: 191-200.

99. Carstensen M, O'Brien DJ, Schmitt SM. Public acceptance as a determinant of management strategies for bovine tuberculosis in free-ranging US wildlife. Veterinary Microbiology 2011; 151: 200-204.

100. Woodroffe R, et al. Bovine tuberculosis in cattle and badgers in localized culling areas. Journal of Wildlife Diseases 2009; 45: 128-143.

101. Meyer ME, Meagher M. Brucellosis in free-ranging bison (Bison bison) in Yellowstone, Grand Teton, and Wood Buffalo National Parks: a review. Journal of Wildlife Diseases 1995; 31: 579-598.
102. VerCauteren K, Shivik J, Lavelle M. Efficacy of an animal-activated frightening device on urban elk and mule deer. Wildlife Society Bulletin 2005; 33: 1282-1287.

103. Mörner T, et al. Surveillance and monitoring of wildlife diseases. Revue Scientifique et Technique de l'Office International des Épizooties 2002; 21: 67-76.

104. Ramsey DS, et al. Management of bovine tuberculosis in free-ranging Michigan White-tailed deer: predictions from a new spatially-explicit model. 60th Annual International Conference of the Wildlife Disease Association. Quebec City, Canada: The Wildlife Disease Association, 2011.

105. Cosgrove MK, et al. Modeling vaccination and targeted removal of white-tailed deer in Michigan for bovine tuberculosis control. Wildlife Society Bulletin 2012; 36: 676-684.

106. Berentsen AR, et al. Active use of coyotes (Canis latrans) to detect bovine tuberculosis in northeastern Michigan, USA. Veterinary Microbiology 2011; 151: 126-32.

107. Sawa TR, Thoen CO, Nagao WT. Mycobacterium bovis infection in wild axis deer in Hawaii. Journal of the American Veterinary Medical Association 1974; 165: 998-999.

108. Whipple DL, Palmer MV. Reemergence of Tuberculosis in Animals in the United States. Washington, DC: ASM Press, 2000, pp. 281-299.

109. Thoen CO, Steele JH, Gilsdorf MJ. Mycobacterium bovis Infection in Animals and Humans, 2nd edn. Boston, Massachusetts: Blackwell Publishers, 2006, pp. 329.

110. Bruning-Fann CS, et al. Mycobacterium bovis in coyotes from Michigan. Journal of Wildlife Diseases 1998; 34: 632-6.

111. Kaneene JB, et al. Epidemiologic investigation of Mycobacterium bovis in a population of cats. American Journal of Veterinary Research 2002; 63: 1507-1511.

112. Carstensen M, et al. Managing bovine tuberculosis in white-tailed deer in Northwestern Minnesota: a 2008 Progress Report. St. Paul, MN: Minnesota Department of Natural Resources, 2009.

113. LeDune EK. Post-mortem findings in deer. In: State of New York CD, 26th Annual Report to the Legislature for the Year 1936. Albany, NY: J. B. Lyon Company, 1937, pp. 466.

114. Wagner BA. Risk assessment for Mycobacterium bovis in Cervidae. Animal Health Insight 1993 (Summer), pp. 22-32.

115. Joly DO, Messier F. Factors affecting apparent prevalence of tuberculosis and brucellosis in wood bison. Journal of Animal Ecology 2004; 73: 623-631.

116. Lutze-Wallace C, et al. Strain typing of Mycobacterium bovis from a 1978 case of tuberculosis in a wolf (Canis lupis) from Manitoba. Canadian Veterinary Journal 2005; 46: 502-503. 